\title{
Gamma Radiolytic Formation of Alloyed Ag-Pt Nanocolloids
}

\author{
M. K. Temgire, ${ }^{1}$ Jayesh Bellare, $^{2}$ and S. S. Joshi ${ }^{3}$ \\ ${ }^{1}$ Elkay Chemicals Private Limited, Bhosari, Pune 411061, India \\ ${ }^{2}$ Department of Chemical Engineering, Indian Institute of Technology Bombay, Mumbai 400076, India \\ ${ }^{3}$ Department of Chemistry, University of Pune, Pune 411007, India \\ Correspondence should be addressed to S.S. Joshi, ssjoshi@chem.unipune.ernet.in
}

Received 24 September 2010; Revised 30 January 2011; Accepted 7 February 2011

Academic Editor: Günther Rupprechter

Copyright $\odot 2011$ M. K. Temgire et al. This is an open access article distributed under the Creative Commons Attribution License, which permits unrestricted use, distribution, and reproduction in any medium, provided the original work is properly cited.

Colloidal dispersions of Ag-Pt composite nanoparticles were prepared by gamma radiolysis technique in the presence of nonionic surfactant Brij'97. Simultaneous as well as sequential reduction methods were employed in order to study the structural formation of Ag-Pt bimetallic clusters. Similar shape and trend was observed in optical spectra for both methods. Radiolysis yielded nearly spherical Ag-Pt bimetallic clusters by use of $\mathrm{AgNO}_{3}$ instead of $\mathrm{AgClO}_{4}$. The disappearance of the silver resonance and the simultaneous growth of the $260 \mathrm{~nm}$ resonance are independent of cluster structure and degree of alloying. To understand formation of Ag-Pt aggregate, the optical studies were also done as a function of amount of dose absorbed, concentration of surfactant, that is, Brij'97. The shape of the absorption spectrum did not change with increase in gamma radiation dose. TEM analysis exhibited fine dispersions of Ag-Pt clusters surrounded by a mantle when capped with Brij'97. The particle size obtained was in the range of 5-9 $\mathrm{nm}$. On the basis of optical, XRD, and TEM analysis, alloy formation is discussed.

\section{Introduction}

Since 1973 [1], much interest has been developed in synthesis of ultrafine metal clusters, which exhibit size dependent physicochemical properties in a liquid environment distinct from those of bulk metals [2-4]. Composite clusters alloyed or bilayered are receiving special attention in catalytic research as they have good chemical stability, selectivity, and high dispersity giving rise to enhanced catalytic activity in comparison with individual monometallic components [5, 6]. Several routes are reported for nanoparticle preparation. Some of these methods include chemical reduction $[7,8]$, photolytic reduction [9], radiolytic reduction [10-12], sonochemical method $[13,14]$. Radiation-induced generation of metal clusters has been proved to be a powerful method of synthesis at room temperature, as it produces homodispersed nanoclusters without any disturbance of chemical impurities. Several bimetallic aggregates have been synthesized at room temperature by radiolytic reduction method [15-18].

While reviewing the work done for the past decade by Mulvaney's and Henglein's group [19-21], nanosize Ag particles in aqueous solutions have been considered as an intermediate state between the single atom and the bulk material, with a series of surprising properties. It was shown that not only the size, the shape, and the chemical surface modification but also the electron density increase in silver nanoparticles significantly alters the optical properties of silver sols. A blue shift of the Ag plasmon absorption band resulting from the electronic polarization of $\mathrm{Ag}$ particles was observed for aqueous silver sols in the case of electron transfer from the free radicals generated radiolytically or photolytically $[22,23]$, due to the chemisorptions of nucleophilic agents (e.g., Phosphine), and as a result of the underpotential deposition of cadmium and lead on the silver nanoparticles [24-27]. Even a mere addition of sodium borohydride into the aqueous sol prepared using citrate as a reducing agent increased the electron density on the particles and caused the blue shift of the silver plasmon absorption band [28]. The electrons accumulated on the Ag particles can take part in the redox reactions, that is, Ag particles play the role of the nanoelectrodes which are "not charged by an outer potential source, but internally by chemical electron transfer reaction."

In Au-Ag system, it has been shown how segregation or alloying of metals can be controlled by the reduction rate as a function of dose absorbed [29]. The bimetallic character is evidenced by the spectral changes. Due to the high catalytic 
activity of $\mathrm{Ag}, \mathrm{Pd}, \mathrm{Au}$, and $\mathrm{Pt}$, their bimetallic clusters have attracted attention, for example, Pd-Pt [30] and Ag-Pt [3133]. It has been observed by Belloni et al. that a bilayered cluster of Au core-Pd shell is formed at low-dose rate and alloyed clusters at high-dose rate. Au-Ag [34], Au-Pt [35], Au-Pd [36-38], Ag-Pd [39], and Ag-Rh [40] are studied in great detail.

The aim of the present work is to check and confirm the formation of intermetallic character of Ag-Pt by systematically studying the evolution of optical spectra with increasing dose using surfactant Brij'97 by simultaneous and sequential reduction methods. Brij'97 is nonionic surfactant generally called poly (10) oxyethylene oleyl ether (POE). In general, increasing alkyl group length will decrease water solubility; increasing the length of POE will increase water solubility. Due to their amphiphilic character, detergent molecules aggregate in solution to form micelles. They can also align at aqueous/nonaqueous interfaces, reducing surface tension, increasing miscibility, and stabilizing emulsions. The surfactants are known to influence the coalescence and also the kinetics of bimetallic cluster growth alloyed or segregated. To understand the formation of alloy nanoparticles, several experiments were carried out by varying total dose absorbed, concentration of surfactant, concentration of precursor salts, and type of counter ion added. The alloy formation and morphology of these bimetallic particles are investigated by UV-visible spectroscopy, X-ray diffractometry (XRD), and transmission electron microscopy (TEM) analyses.

\section{Materials and Methods}

2.1. Chemicals and Materials. All reagents were pure grade chemicals. $\mathrm{AgNO}_{3}, \mathrm{AgClO}_{4}$, and $\mathrm{H}_{2} \mathrm{PtCl}_{6}$ were from Fluka, Switzerland, propan-2-ol was from Qualigens, India, and the commercial nonionic surfactant used was Brij'97 (poly-(10)oxyethylene oleyl ether) purchased from Altas, USA.

2.2. Preparation of Nanosize Silver-Platinum Colloid by $\gamma$ Irradiation. The silver-platinum nanosize colloid was prepared by $\gamma$-irradiation using a ${ }^{60} \mathrm{Co}$ source at a dose rate of $2.0 \mathrm{kGy} / \mathrm{hr}$. The maximum gamma radiation dose delivered was $16 \mathrm{kGy}$ in order to ensure complete reduction of all ions. Sequential as well as simultaneous reduction methods were employed and compared for the formation of $\mathrm{Ag}-\mathrm{Pt}$ system using Brij'97. In simultaneous reduction method, the solutions of $\mathrm{AgNO}_{3}\left(1 \times 10^{-3} \mathrm{M}\right), \mathrm{H}_{2} \mathrm{PtCl}_{6}\left(1 \times 10^{-3} \mathrm{M}\right)$, and Brij'97 $\left(1 \times 10^{-2} \mathrm{M}\right)$ were mixed deareated by passing $\mathrm{N}_{2}$ gas and irradiated in presence of 2-propanol $\left(2 \times 10^{-1} \mathrm{M}\right)$ giving a total dose of $7.9 \mathrm{kGy}$. In the sequential reduction method, silver colloid was first prepared by submitting a deareated $\mathrm{AgNO}_{3}\left(1 \times 10^{-3} \mathrm{M}\right)$, Brij'97 $\left(1 \times 10^{-3} \mathrm{M}\right)$, and 2-propanol $\left(2 \times 10^{-1} \mathrm{M}\right)$ solution to $\gamma$-irradiation at a dose rate of $2.0 \mathrm{kGy} / \mathrm{hr}$. Complete reduction of $\mathrm{Ag}$ ions occurred after delivering a total dose up to $13.8 \mathrm{kGy}$. Platinum ions in the form of $\mathrm{H}_{2} \mathrm{PtCl}_{6}\left(1 \times 10^{-3} \mathrm{M}\right)$ were then injected into the silver colloid and the solution was again exposed to $\gamma$ irradiation at a dose from $0.5 \mathrm{kGy}$ to $8.0 \mathrm{kGy}$.
The radiolytic reduction mechanism is well known [41]. During radiolysis of aqueous solution initially radiolysis of water takes place where hydrated electrons $\mathrm{e}_{\mathrm{aq}}{ }^{-}, \mathrm{H}^{\bullet}, \mathrm{OH}^{\bullet}$, and $\mathrm{HO}_{2}$ radicals and molecular products $\mathrm{H}_{2} \mathrm{O}_{2}$ and $\mathrm{H}_{2}$ are formed,

$$
\mathrm{OH}^{\bullet}+\mathrm{CH}_{3} \mathrm{CH}(\mathrm{OH}) \mathrm{CH}_{3} \longrightarrow \mathrm{H}_{2} \mathrm{O}+\mathrm{CH}_{3} \mathrm{C}^{\bullet}(\mathrm{OH}) \mathrm{CH}_{3} \text {. }
$$

Second carbon atom is attacked and a secondary radical $\mathrm{CH}_{3} \mathrm{C}^{\bullet}(\mathrm{OH}) \mathrm{CH}_{3}$ is formed which efficiently reduces the precursor metal ions $\mathrm{M}^{+}$to $\mathrm{M}^{\circ}$ when adsorbed on clusters as shown below:

$$
\begin{gathered}
\mathrm{e}_{\mathrm{aq} \cdot}{ }^{-}+\mathrm{M}^{+} \longrightarrow \mathrm{M}^{\circ} \\
n \mathrm{M}^{\circ} \longrightarrow \mathrm{M}_{2} \longrightarrow \cdots \mathrm{M}_{n} \cdot \cdots \mathrm{M}_{\mathrm{agg} .}
\end{gathered}
$$

\subsection{Characterization of Colloidal Ag-Pt Nanoparticles}

2.3.1. Spectrophotometric Measurement. Complete reduction of $\mathrm{Ag}$ ions was monitored by optical spectra on a Hitachi 220A spectrophotometer, which gave no change in absorption spectra at $410 \mathrm{~nm}$ after delivering a total dose up to $13.8 \mathrm{kGy}$. The optical absorption spectra were also taken for various amounts of dose absorbed until no more changes occurred. Individual component spectra were taken, and it was checked that Brij'97 is not reducing the precursor $\mathrm{AgNO}_{3}$ and $\mathrm{H}_{2} \mathrm{PtCl}_{6}$ salts before irradiation.

In both methods of reduction employed for $\mathrm{Ag}-\mathrm{Pt}$ system, the complete disappearance of the Ag plasmon peak was observed from the very beginning. After irradiation, the solutions remained colloidal and stable for a couple of days.

2.3.2. HR-TEM Analyses. TEM analyses for these bimetallic particles were carried out with Philips (model CM200) operated at $200 \mathrm{kV}$. Specimens for TEM were prepared by drying under nitrogen atmosphere droplets of colloidal dispersion on a carbon-supported formvar-coated copper grid. Sizes of more than 200 particles were measured on micrographs to obtain size histograms. Selected area electron diffraction (SAED) was employed for structural characterization. The electron diffraction pattern shows fcc structure from polycrystalline sample.

2.3.3. XRD Measurements. The X-ray diffraction patterns were taken on a Philips powder X-Ray Diffractometry (PW 1840). These patterns were compared with ASTM data (ASTM card no. $783 \& 802$ ) of bulk Ag and Pt. The size of the nanoclusters was approximately estimated from Scherer formula.

\section{Results and Discussion}

3.1. Optical Studies. Colloidal dispersions of metals exhibit absorption bands or broad regions of absorption in UVvisible region. These are due to the excitation of plasmon resonances or interband transitions and are a characteristic property of the metallic nature of the particles. The optical 


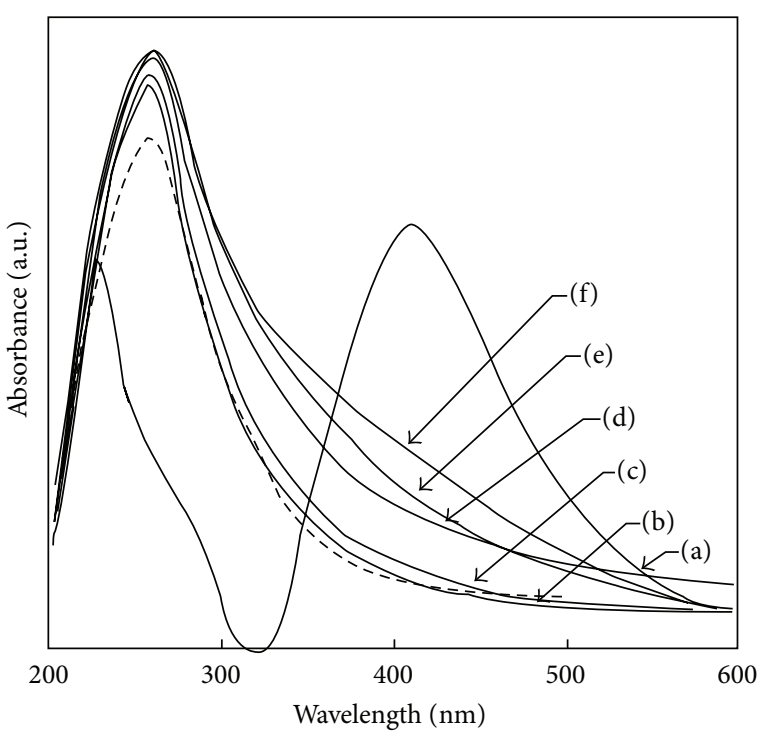

Figure 1: Absorption spectra of Ag-Pt particles prepared by both sequential (b-f) and simultaneous methods. (a) depicts Ag plasmon peak obtained after irradiation for a dose of $13.8 \mathrm{kGy}$. Dotted line depicts the simultaneous reduction of $\mathrm{AgNO}_{3}$ and $\mathrm{H}_{2} \mathrm{PtCl}_{6}$ with Brij'97 for a total dose of $7.9 \mathrm{kGy} . \mathrm{AgNO}_{3}=\left[1 \times 10^{-3} \mathrm{M}\right]$, Brij' $97=$ $\left[1 \times 10^{-2} \mathrm{M}\right], \mathrm{H}_{2} \mathrm{PtCl}_{6}=\left[1 \times 10^{-3} \mathrm{M}\right]$ in an inert atmosphere; optical path: $1 \mathrm{~cm}$.

properties of silver were studied using PVA [42, 43]. Arnold and Borders $[44,45]$ have utilized optical spectra to estimate the particle size as a function of wavelength by applying Mie theory. The absorption measurements of the particles can be evaluated by using Mie theory [46] and its expanded versions $[47,48]$. For spherical particles having a $10 \mathrm{~nm}$ diameter, the absorption spectra are characterized by a plasmon peak [4951]. Colloidal Ag is useful for studying the electronic changes that occur upon chemical modification of the surface.

The absorption band of silver particles is strongly influenced by chemisorbed molecules. The surface plasmon spectrum of metal nanoclusters is highly dependent on the surrounding environment (i.e., metal ion concentration, amount of polymer or surfactant, $\mathrm{pH}$, etc.) and also on the amount of dose absorbed in case of radiolytic preparation.

Figure 1(a) shows the surface plasmon band for Ag particles at $410 \mathrm{~nm}$ obtained after irradiation in the presence of Brij' 97 for a dose of $13.8 \mathrm{kGy}$. For sequential reduction method, $\mathrm{Pt}$ ions in the form of $\mathrm{H}_{2} \mathrm{PtCl}_{6}\left(1 \times 10^{-3} \mathrm{M}\right)$ were added to the irradiated silver colloid capped with Brij' 97 and again subjected to $\gamma$-irradiation. The absorption spectra (b to $\mathrm{f}$ ) were then recorded as a function of dose absorbed after addition of Pt ions. For even low doses, the characteristic surface plasmon resonance peak for silver completely disappears. The same spectra show concomitantly the growth of a band at ca. $260 \mathrm{~nm}$ for the Ag-Pt colloids and may be some isolated Pt colloids with Brij'97. This value of the Pt resonance is red shifted with respect to the band expected for individual Pt-clusters in water [52]. Henglein et al. also have obtained an absorption band at ca. $260 \mathrm{~nm}$ which was attributed to aggregates of Pt particles. We also mention here that a similar absorption band has been observed by Rivadulla et al. [53] for Pt synthesized in micro emulsions.

Henglein estimated reduction potentials of $\mathrm{Ag}^{+}$to $\mathrm{Ag}^{\circ}$ in acidic solution is

$$
\mathrm{Ag}^{+}+\mathrm{e}^{-} \longrightarrow \mathrm{Ag}^{\circ} \quad \mathrm{E}^{\circ}=-1.8 \mathrm{~V} / \mathrm{NHE},
$$

whereas Pt gets reduced in two steps:

$$
\begin{gathered}
\mathrm{Pt}^{4+} \mathrm{Cl}_{6}^{2-}+2 \mathrm{e}^{-} \longrightarrow \mathrm{PtCl}_{4}{ }^{2-}+2 \mathrm{Cl}^{-} \quad \mathrm{E}^{\circ}=+0.66 \mathrm{~V}, \\
\mathrm{Pt}^{2+}+2 \mathrm{e}^{-} \longrightarrow \mathrm{Pt}^{\circ} \quad \mathrm{E}^{\circ}=+0.7 \mathrm{~V} .
\end{gathered}
$$

The reduction potential being lower, silver gets reduced preferentially and it transfers electrons to Pt and thereby reducing Pt stepwise. Irrespective of the procedure, Ag plasmon is disappearing which can be explained on the basis of reduction potentials of silver and platinum.

In case of simultaneous reduction method as indicated by the dotted line in Figure 1(b), the characteristic plasmon peak for Ag did not appear from the very beginning. This indicates bimetallic formation of Ag-Pt nanoparticles in both simultaneous and sequential methods.

The spectra exhibit the same shape at all doses confirming alloy formation which is in agreement with Remita's group.

In case of bimetallic system, the evolution of the optical absorption spectra with the dose of irradiation is very informative. In order to check the formation of intermetallic character of Ag-Pt, optical spectra were studied with increasing amount of dose.

Experiments were performed to check the interaction stepwise between irradiated silver colloid and precursor $\mathrm{Pt}^{4+}$ ions in the form of $\mathrm{H}_{2} \mathrm{PtCl}_{6}$.

Figure 2 shows evolution of optical spectra under identical synthetic conditions. Figure 2(a) shows the formation of silver colloid at about $410 \mathrm{~nm}$. To this colloidal Ag solution, $\mathrm{Pt}^{4+}$ ions were then added in the form of $\mathrm{H}_{2} \mathrm{PtCl}_{6}$. Immediately, light yellow color vanished and absorption spectrum showed complete disappearance of Ag plasmon peak and simultaneous growth of a band at ca. $262 \mathrm{~nm}$ of $\mathrm{Pt}$ colloid. In the next experiment, $\mathrm{Pt}^{4+}$ ions were added along with 2-propanol (Figure 2(b)) to the irradiated silver colloid. No change in size and shape of the curve was observed except reduction in the intensity of silver plasmon peak. Later, the reverse reduction method was employed, that is, $\mathrm{H}_{2} \mathrm{PtCl}_{6}$ was irradiated in presence of Brij' 97 and 2-propanol for a dose of $1.9 \mathrm{kGy}$, and $\mathrm{AgNO}_{3}$ was then added to the platinum colloid formed. The solid line shows Ag-Pt bimetallic formation, and the dotted line shows isolated Pt particles plasmon peak (Figure 2(c)).

3.2. TEM and XRD Studies. Figures $3(\mathrm{a}), 3(\mathrm{~b})$, and $3(\mathrm{c})$ show the transmission electron micrographs with their electron diffraction patterns for pure Ag, pure Pt, and bimetallic AgPt nanoparticles, respectively, along with corresponding size histograms inset plotted for these particles by simultaneous reduction method. The selected area diffraction pattern (Figure 3(c)) indicates well developed hkl planes and the $d$ values (interplanar spacings) are intermediate between 


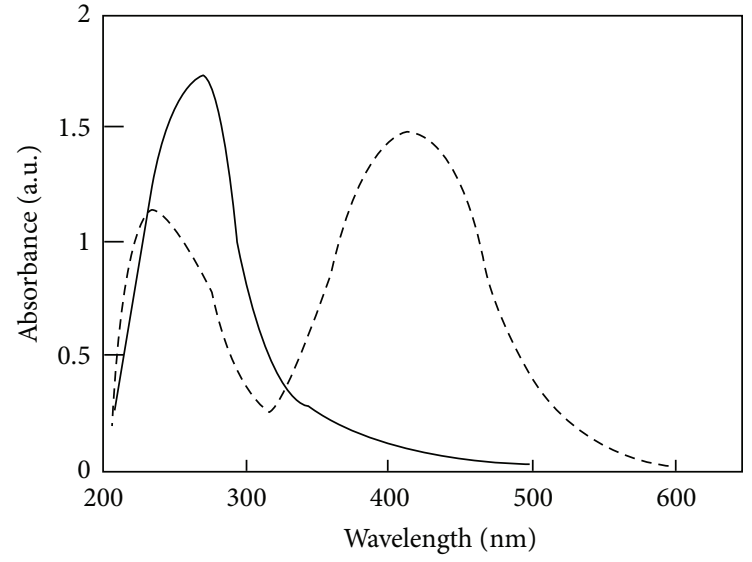

(a)

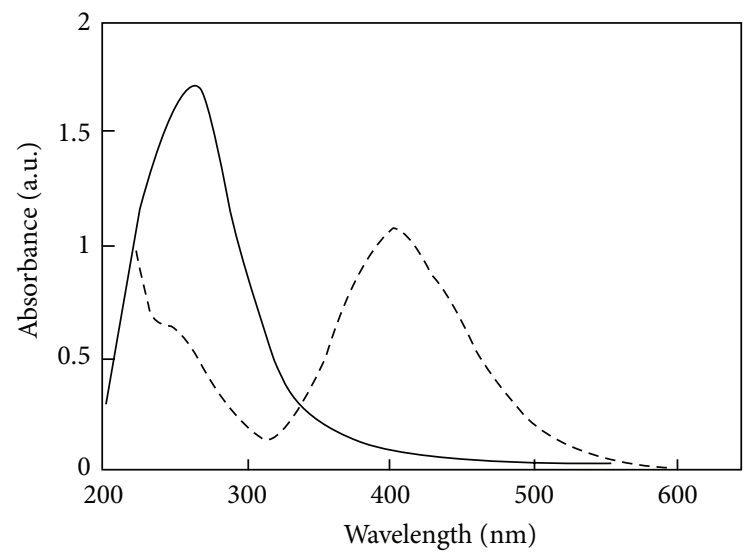

(b)

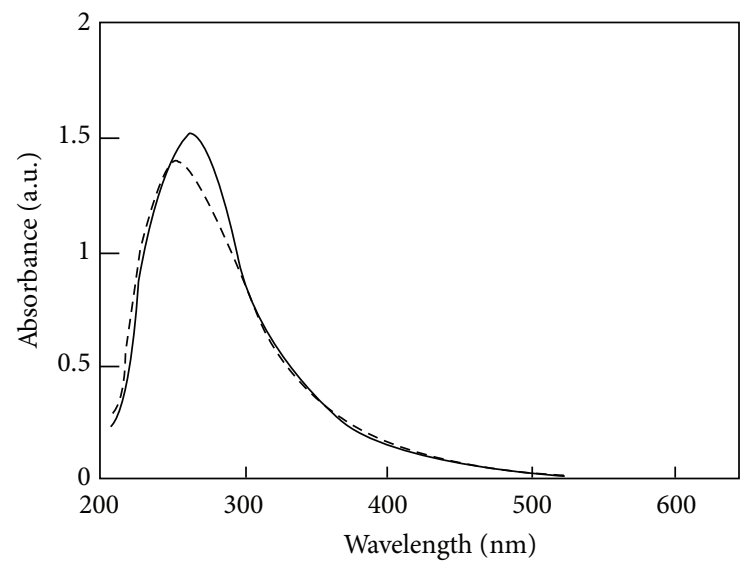

(c)

Figure 2: (a) Absorption spectra of Ag nanoparticles initially synthesized by gamma-radiolysis at a dose $2.0 \mathrm{kGy}$ using Brij' 97 . $\mathrm{AgNO}_{3}=\left[1 \times 10^{-3} \mathrm{M}\right]$, Brij'97 = $\left[1 \times 10^{-2} \mathrm{M}\right]$, 2-propanol $=[2 \times$ $\left.10^{-1} \mathrm{M}\right]$, and $\mathrm{H}_{2} \mathrm{PtCl}_{6}=\left[1 \times 10^{-3} \mathrm{M}\right]$. Absorption spectra recorded immediately after addition of $\mathrm{Pt}^{4+}$ ions. (b) $\mathrm{Pt}^{4+}$ ions in presence of 2-propanol were added to irradiated silver colloid shown by the dotted line. (c) Addition of $\mathrm{AgNO}_{3}$ and 2-propanol to irradiated $\mathrm{Pt}$ colloid shown by the dotted line in an inert atmosphere. Optical path: $1 \mathrm{~cm}$. pure Ag and pure Pt. The geometry of the alloy structure is face centered cubic (fcc). The micrographs show clearly split Debye Scherer rings. The $d$ values for (111) plane from electron diffraction for bulk $\mathrm{Ag}$ and bulk $\mathrm{Pt}$ are $2.359 \AA$, $2.265 \AA$, respectively, whereas synthesized Ag-Pt clusters show around $2.76 \AA$. This shows that there is a shift from the standard $d$ values of $\mathrm{Ag}$ and Pt clusters of about $0.4 \AA$. An accurate determination of lattice parameters intermediate between those of $\mathrm{Ag}$ and $\mathrm{Pt}$ with SAED were possible with the number of concentric diffraction spots to confirm alloy formation.

Under the given synthesis conditions, the average size of pure Ag clusters and pure Pt clusters is $14.9,11.5 \mathrm{~nm}$ whereas that of Ag-Pt composite clusters is $12.5 \mathrm{~nm}$, smaller than silver particles. The pure Ag and Pt particles are spherical in shape and Ag-Pt composite particles are slightly elongated in shape. The experimental results also support the theoretical calculations for ellipsoids in the quasistatic regime [54]. The deformation from the spherical shape can be explained to be due to the surface diffusion preferentially directed normal to the compression direction which gives rise to changes of the cluster shape from spherical to oblate spheroid shape [55].

It should be noticed that in this concentration range, the size distribution is unimodal. If alloy particles are not formed, it would lead to a broad or bimodal size distribution due to different growth rates for the two metal colloids, which may be in turn correlated to surface energy $[56,57]$ or cohesive energy [58] of them. However, from Figure 2(c), the measured particle size distributions were unimodal and converged in a fairly narrow range; although helpful, optical absorption measurements could not establish whether $\mathrm{Ag}$ and Pt form a homogeneous alloy or if the nanoparticles have a core-shell structure suggesting that the particles are formed.

Figures 4 and 5 depict X-ray diffraction patterns for AgPt bimetallic clusters prepared by sequential and simultaneous reduction method at a high dose of 16 and $8 \mathrm{kGy}$, respectively. These patterns of Ag-Pt composite clusters were taken for varying amount of Brij' 97 , that is, $1 \times 10^{-3} \mathrm{M}, 2 \times$ $10^{-2} \mathrm{M}$, and $5 \times 10^{-2} \mathrm{M}$ in the case of sequential method, other conditions remaining same. While in simultaneous reduction method, X-ray diffraction patterns were taken as a function of Brij' 97 concentrations $1 \times 10^{-2} \mathrm{M}$ and $2 \times$ $10^{-2} \mathrm{M}$. All these patterns were compared with ASTM data for bulk silver and bulk platinum (ASTM card no. 783 and 802 , resp.). The comparison between theoretical and experimental $d$ values primarily confirms Ag-Pt bimetallic aggregate formation. As no characteristic peak was observed for pure Ag and pure Pt but all peaks were intermediate indicating intermetallic characters of Ag-Pt system.

The $d$ values for bulk Ag and bulk Pt are $2.359 \AA, 2.265 \AA$, respectively whereas synthesized Ag-Pt clusters show around $2.76 \AA$ for (111) plane. The deviation is about $0.4 \AA$ from the standard $d$ values. The particle diameter is calculated as a mean of 10 to 11 peaks along with standard deviation. The $d$ values range between $4.1 \mathrm{~nm}$ to $14.2 \mathrm{~nm}$ for $2 \vartheta$ values ranging between $27.9^{\circ}$ to $85.5^{\circ}$.

Table 1 shows the $\mathrm{Ag} / \mathrm{Pt}$ clusters with precursor ratio $1: 1$ for all that are synthesized with sequential reduction method 


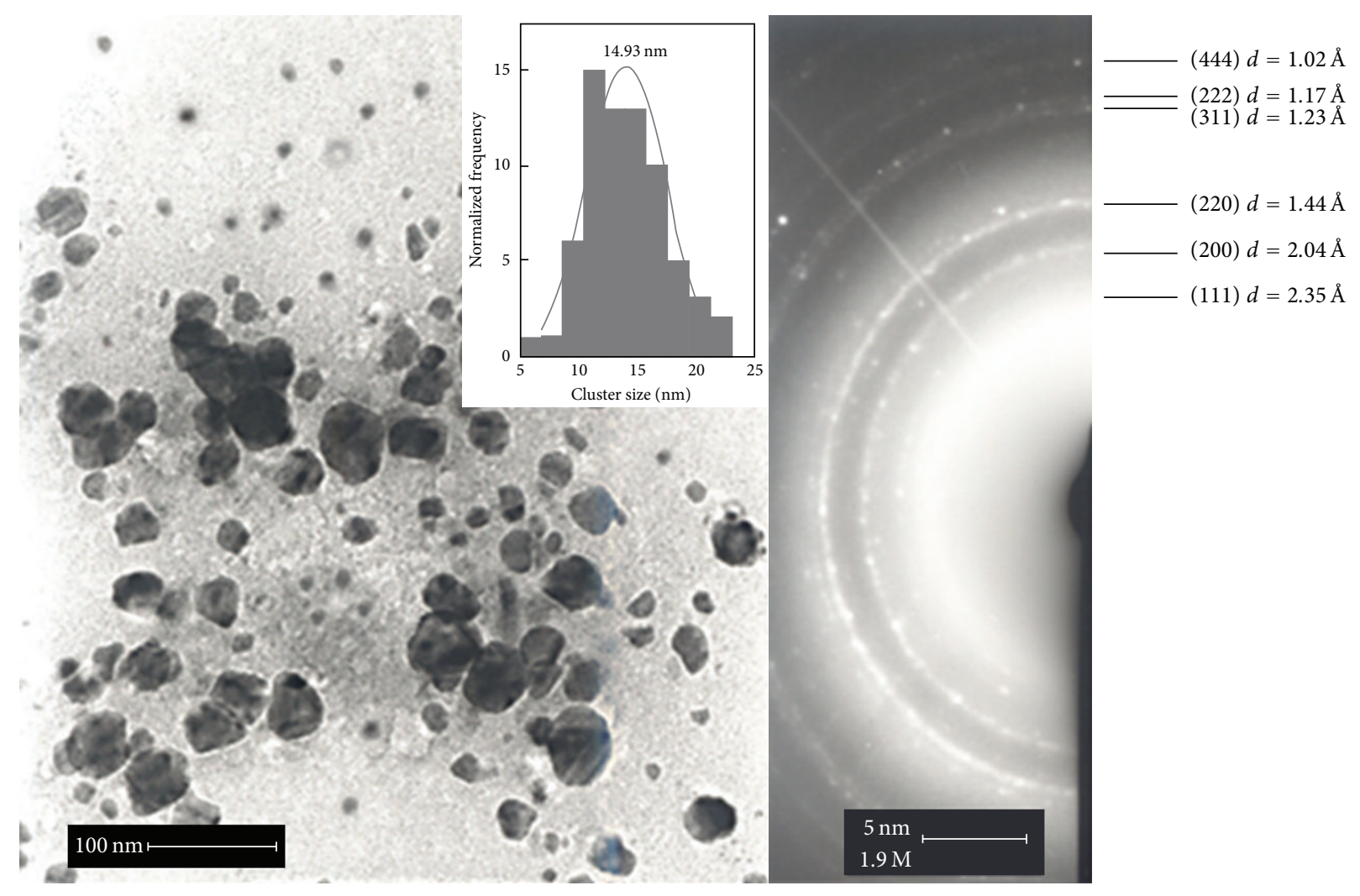

(a)
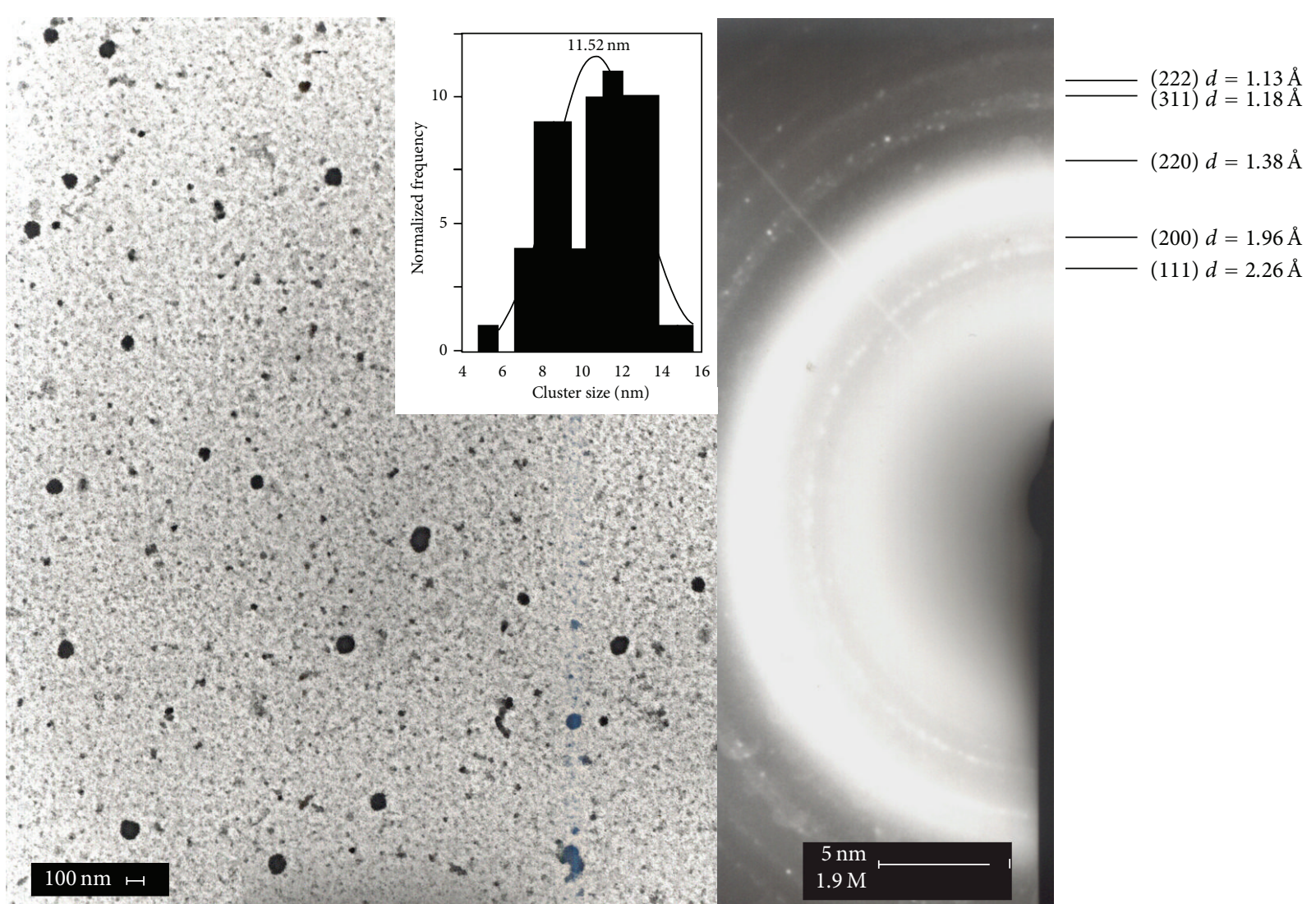

(b)

Figure 3: Continued. 

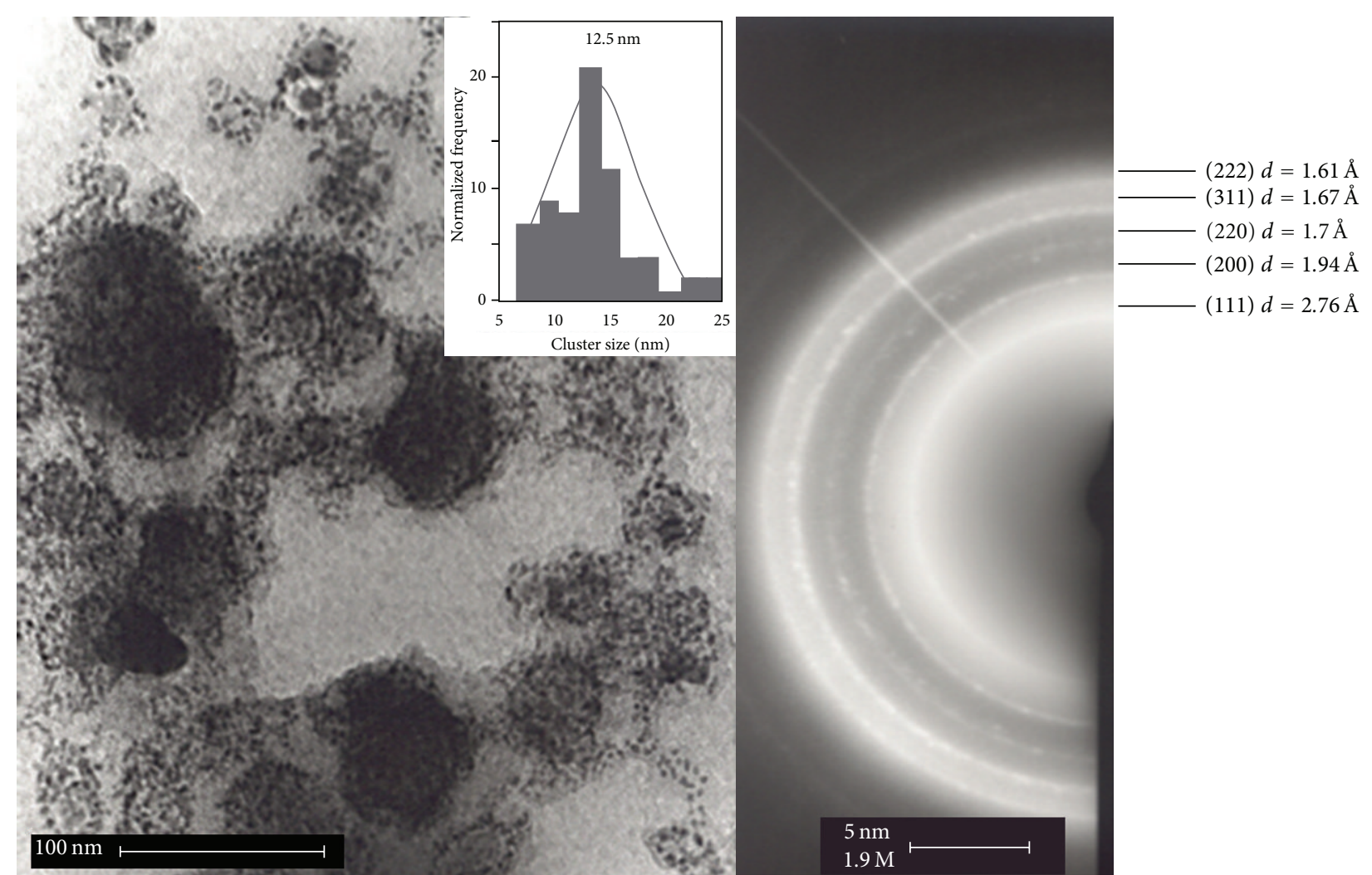

$\begin{array}{lll}10 & 15 & 20 \\ \text { Cluster size }(\mathrm{nm})\end{array}$
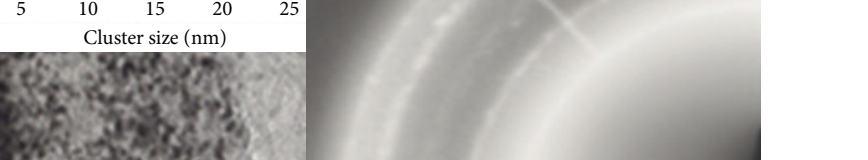
$d=2.76 \AA$

Figure 3: (a) TEM image and electron diffraction spot pattern obtained from Brij' 97 capped Ag nanoparticles by gamma radiolysis. $\mathrm{AgNO}_{3}=$ $\left[1 \times 10^{-3} \mathrm{M}\right]$, Brij' $97=\left[1 \times 10^{-2} \mathrm{M}\right]$, and 2-propanol $=\left[2 \times 10^{-1} \mathrm{M}\right]$ irradiated with a dose of $1.9 \mathrm{kGy}$ in an inert atmosphere. Corresponding size histogram inset of Ag particles. The solid line is a Gaussian fit to the PSD data. (b) TEM image and electron diffraction spot pattern obtained from Brij'97 capped Pt nanoparticles by gamma radiolysis. $\mathrm{H}_{2} \mathrm{PtCl}_{6}=\left[1 \times 10^{-3} \mathrm{M}\right]$, Brij' $97=\left[1 \times 10^{-2} \mathrm{M}\right]$, and 2-propanol $=$ $\left[2 \times 10^{-1} \mathrm{M}\right]$ in an inert atmosphere with a dose of $1.9 \mathrm{kGy}$ corresponding size histogram inset for Pt particles. The solid line is a Gaussian fit to the PSD data. (c) TEM images and electron diffraction spot pattern obtained from Brij'97 capped of Ag-Pt particles by simultaneous reduction method. $\mathrm{AgNO}_{3}=\left[1 \times 10^{-3} \mathrm{M}\right], \mathrm{H}_{2} \mathrm{PtCl}_{6}=\left[1 \times 10^{-3} \mathrm{M}\right]$, Brij'97 $=\left[1 \times 10^{-2} \mathrm{M}\right]$, and 2-propanol $=\left[2 \times 10^{-1} \mathrm{M}\right]$ irradiated with a dose of $7.9 \mathrm{kGy}$ in an inert atmosphere, corresponding size histogram inset for Ag-Pt bimetallic nanoparticles. The solid line is a Gaussian fit to the PSD data.

TABLE 1: TEM and XRD characterization of bimetallic Ag/Pt clusters synthesized at high-dose rate at various Brij'97 concentrations with sequential reduction method (Dose: $16.0 \mathrm{kGy}$ ).

\begin{tabular}{lcccc}
\hline Sample & $\begin{array}{c}{[\mathrm{M}]} \\
(\mathrm{M})\end{array}$ & $\begin{array}{c}{[\text { Brij'97] }} \\
(\mathrm{M})\end{array}$ & $\begin{array}{c}\text { Cluster size } \\
\text { by TEM }(\mathrm{nm})\end{array}$ & $\begin{array}{c}\text { Cluster size } \\
\text { by XRD }(\mathrm{nm})\end{array}$ \\
\hline AgPt-1 & $10^{-3}$ & $10^{-2}$ & 9 & $12-13$ \\
AgPt-2 & $10^{-3}$ & $2 \times 10^{-2}$ & $7-8$ & $8-9$ \\
AgPt-3 & $10^{-3}$ & $5 \times 10^{-3}$ & $5-6$ & $8-9$ \\
Ag-Pt-4 & $10^{-3}$ & $5 \times 10^{-3}$ & - & $9-10$ \\
\hline
\end{tabular}

at various concentrations of Brij'97 done at a high dose (16.0 kGy). Data of the cluster size was characterized by TEM and XRD. The lattice constant of the Ag-Pt clusters were calculated from selected area diffraction measurements and was found to depend linearly on Ag composition (Vegard's law). This result indicates formations of homogeneous alloys, an important size effect seen of mixed Ag-Pt particles are much smaller than the pure silver ones under comparable
TABLE 2: TEM and XRD characterization of bimetallic Ag/Pt clusters synthesized at high-dose rate at various Brij' 97 concentrations with simultaneous reduction method (Dose: $8.0 \mathrm{kGy}$ ).

\begin{tabular}{ccccc}
\hline Sample & $\begin{array}{c}{[\mathrm{M}]} \\
(\mathrm{M})\end{array}$ & $\begin{array}{c}\text { [Brij'97] } \\
(\mathrm{M})\end{array}$ & $\begin{array}{c}\text { Cluster size } \\
\text { by TEM }(\mathrm{nm})\end{array}$ & $\begin{array}{c}\text { Cluster size } \\
\text { by XRD }(\mathrm{nm})\end{array}$ \\
\hline AgPt-5 & $10^{-3}$ & $10^{-2}$ & $7-8$ & $12-13$ \\
AgPt-6 & $10^{-3}$ & $2 \times 10^{-2}$ & $6-7$ & $10-11$ \\
AgPt-7 & $10^{-3}$ & $1 \times 10^{-3}$ & $7-8$ & $10-11$ \\
\hline
\end{tabular}

conditions. The cluster size of $\mathrm{Ag} / \mathrm{Pt}$ cluster with TEM was in the overall range of 5-9 $\mathrm{nm}$, and with XRD, the range was $8-13 \mathrm{~nm}$ at various concentrations of Brij'97.

Table 2 shows the Ag/Pt clusters with all experimental precursor ratios 1:1 with simultaneous reduction method done at a high dose $(8.0 \mathrm{kGy})$. The cluster size of $\mathrm{Ag} / \mathrm{Pt}$ particles determined by TEM was in the range of $6-8 \mathrm{~nm}$ and by using XRD in the range of $10-13 \mathrm{~nm}$. The small 


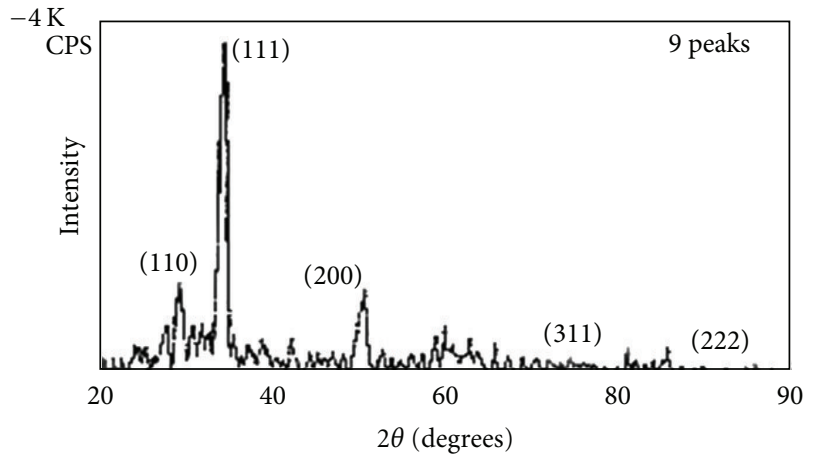

(a)

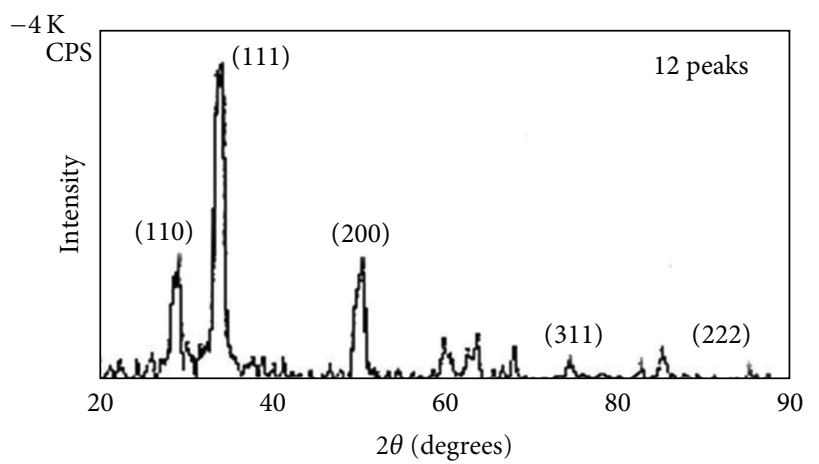

(b)

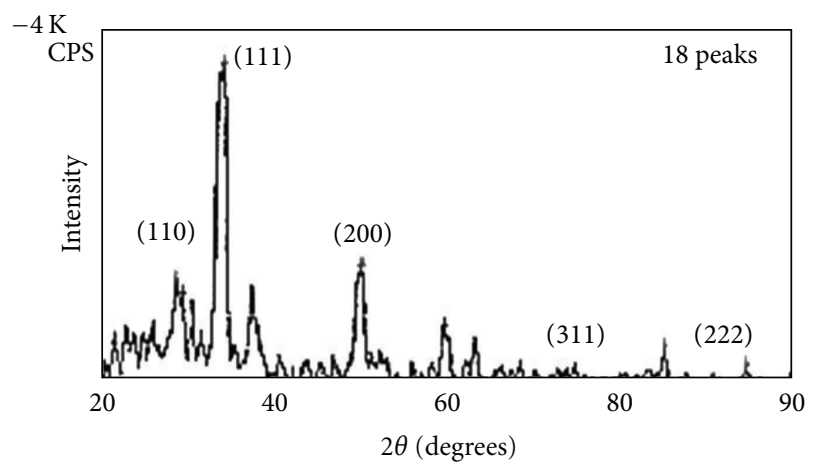

(c)

Figure 4: X-ray diffractograms of Ag-Pt bimetallic particles by sequential reduction method for different amounts of Brij'97 (a) $\left[1 \times 10^{-3} \mathrm{M}\right](\mathrm{b})\left[2 \times 10^{-2} \mathrm{M}\right](\mathrm{c})\left[5 \times 10^{-2} \mathrm{M}\right]$ concentration of $\mathrm{AgNO}_{3}$ and $\mathrm{H}_{2} \mathrm{PtCl}_{6}$ being $\left[1 \times 10^{-3} \mathrm{M}\right]$.

size shown by TEM is due to immediate analysis of the colloidal solution whereas XRD studies were done after drying the colloidal solution after some time interval. There is no significant deviation in the particle size as a function of concentration.

It was observed that not only surfactant concentration and type of surfactant that affect the formation and distribution of particles, but the type of irradiation also changes the morphology [43]. Using similar conditions, Ag$\mathrm{Pt}$ particles were formed by simultaneous irradiation of both salts, and TEM image showed fine particles with no cluster formation.

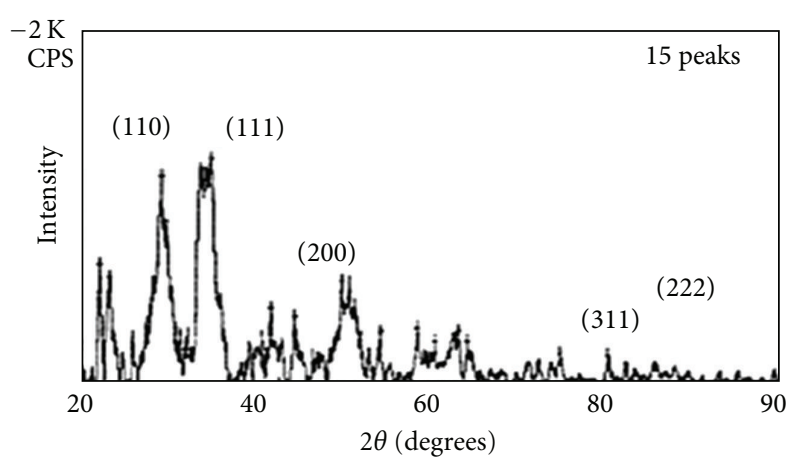

(a)

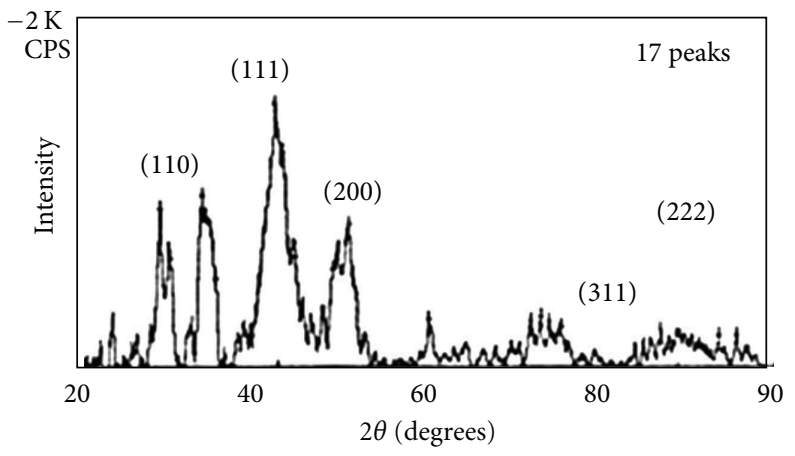

(b)

Figure 5: X-ray diffractograms of Ag-Pt bimetallic particles by simultaneous reduction method for different amounts of Brij'97 (a) $\left[1 \times 10^{-3} \mathrm{M}\right](\mathrm{b})\left[2 \times 10^{-2} \mathrm{M}\right]$ concentration of $\mathrm{AgNO}_{3}$ and $\mathrm{H}_{2} \mathrm{PtCl}_{6}$ being $\left[1 \times 10^{-3} \mathrm{M}\right]$.

Colloidal particles are subjected to a number of attractive and repulsive forces and the stability of dispersion depends on the interplay of these various forces. These forces and hence the stability of dispersions can be altered or controlled by the adsorption of ions, surfactants, or polymers at the solid-liquid interface. Adsorption of surfactants and polymers depends on the nature of surfactants and polymers. Nonionic surfactants adsorb primarily through hydration or hydrogen bond interactions [59]. In an oxygen-free atmosphere, $\mathrm{H}^{\bullet}$ and $\mathrm{OH}^{\bullet}$ radicals lead to increased viscosity due to cross linking for Brij'97. In the liquid phase, the products formed by $\gamma$-irradiation are predominantly by $\mathrm{C}-$ $\mathrm{O}$ bond cleavage and to a lesser extent, $\mathrm{C}-\mathrm{H}$ and $\mathrm{C}-\mathrm{C}$ bond rupture; $\mathrm{H}_{2}$ is lost mainly from carbon atom adjacent to the ether group.

Our present results on optical, XRD, and TEM indicate bimetallic aggregates with alloy formation to some extent. Initially, silver must be getting reduced due to its higher reduction potential and reducing platinum. Tetravalent $\mathrm{Pt}$ ions also get reduced into divalent $\mathrm{Pt}$ ions by hydrated electron and isopropyl radical. Then the divalent platinum ions disproportionate and are also reduced. Depending on the dose absorbed, reduced atoms, clusters, and excess ions may get associated with forming mixed bimetallic clusters. Further coalescence of the primary bimetallic complex species keeps the metal alloyed. 


\section{Conclusion}

Gamma radiolysis is a powerful method to synthesize mono- and bimetallic nanoparticles. It gives homodispersed, ultrafine particles without disturbing chemical impurities. By changing the amount of dose absorbed, the particle size can be controlled. Radiolysis yielded nearly spherical Ag-Pt bimetallic clusters by use of $\mathrm{AgNO}_{3}$. Ag-Pt alloyed particles and bimetallic aggregates were prepared by gamma radiolysis using Brij'97. Simultaneous and sequential reduction methods were followed. In both methods, the disappearance of Ag plasmon peak was observed when Pt is added to Ag nanoparticles, independent of cluster structure and degree of alloying from the very beginning. TEM analysis exhibited dispersion of fine particles surrounded by a mantle when capped with Brij'97.

\section{Acknowledgments}

The authors gratefully acknowledge valuable suggestions and discussion with Professor J. Belloni, financial support from the Department of Atomic Energy, Government of India, and partial financial support from Unilever Industries (Pvt.) Ltd. M. K. Temgire and Dr. S. S. Joshi Sophisticated Analytical Instruments Facility (RSIC), IIT-Bombay for the TEM facility.

\section{References}

[1] M. O. Delcourt and J. Belloni, "Capture of hydrazine precursors by copper(I) ions during $\gamma$-radiolysis of liquid ammonia," Radiochemical and Radioanalytical Letters, vol. 13, pp. 329338, 1973.

[2] A. Henglein, "Mechanism of reactions on colloidal microelectrodes and size quantization effects," Topics in Current Chemistry, vol. 143, pp. 113-180, 1988.

[3] A. Henglein, "Physicochemical properties of small metal particles in solution: "Microelectrode" reactions, chemisorption, composite metal particles, and the atom-to-metal transition," Journal of Physical Chemistry, vol. 97, no. 21, pp. 5457-5471, 1993.

[4] J. Belloni, "Metal nanocolloids," Current Opinion in Colloid and Interface Science, vol. 1, pp. 184-196, 1996.

[5] N. Toshima and Y. Wang, "Preparation and catalysis of novel colloidal dispersions of copper/noble metal bimetallic clusters," Langmuir, vol. 10, no. 12, pp. 4574-4580, 1994.

[6] M. M. Telkar, C. V. Rode, R. V. Chaudhari, S. S. Joshi, and A. M. Nalawade, "Shape-controlled preparation and catalytic activity of metal nanoparticles for hydrogenation of 2-butyne1,4-diol and styrene oxide," Applied Catalysis A, vol. 273, no. 1-2, pp. 11-19, 2004.

[7] J. H. Sinfelt, "Structure of bimetallic clusters," Accounts of Chemical Research, vol. 20, no. 4, pp. 134-329, 1987.

[8] T. Yonezawa and N. Toshima, "Mechanistic consideration of formation of polymer-protected nanoscopic bimetallic clusters," Journal of the Chemical Society, Faraday Transactions, vol. 91, no. 22, pp. 4111-4119, 1995.

[9] H. H. Huang, X. P. Ni, G. L. Loy et al., "Photochemical formation of silver nanoparticles in poly(N-vinylpyrrolidone)," Langmuir, vol. 12, no. 4, pp. 909-912, 1996.
[10] J. Khatouri, M. Mostafavi, J. Amblard, and J. Belloni, "Radiation-induced copper aggregates and oligomers," Chemical Physics Letters, vol. 191, no. 3-4, pp. 351-356, 1992.

[11] A. Henglein, B. G. Ershov, and M. Malow, "Absorption spectrum and some chemical reactions of colloidal platinum in aqueous solution," Journal of Physical Chemistry, vol. 99, no. 38, pp. 14129-14136, 1995.

[12] S. S. Joshi, S. F. Patil, V. Iyer, and S. Mahumuni, "Radiation induced synthesis and characterization of copper nanoparticles," Nanostructured Materials, vol. 10, no. 7, pp. 1135-1144, 1998.

[13] K. Okitsu, H. Bandow, Y. Maeda, and Y. Nagata, "Sonochemical preparation of ultrafine palladium particles," Chemistry of Materials, vol. 8, no. 2, pp. 315-317, 1996.

[14] Y. Mizukoshi, K. Okitsu, Y. Maeda, T. A. Yamamoto, R. Oshima, and Y. Nagata, "Sonochemical preparation of bimetallic nanoparticles of gold/palladium in aqueous solution," Journal of Physical Chemistry B, vol. 101, no. 36, pp. 7033-7037, 1997.

[15] J. L. Marignier, J. Belloni, M. O. Delcourt, and J. P. Chevalier, "Microaggregates of non-noble metals and bimetallic alloys prepared by radiation-induced reduction," Nature, vol. 317, no. 6035, pp. 344-345, 1985.

[16] S. Remita, M. Mostafavi, and M. O. Delcourt, "Bimetallic Ag$\mathrm{Pt}$ and Au-Pt aggregates synthesized by radiolysis," Radiation Physics and Chemistry, vol. 47, no. 2, pp. 275-279, 1996.

[17] H. Remita, J. Khatouri, M. Tréguer, J. Amblard, and J. Belloni, "Silver-palladium alloyed clusters synthesized by radiolysis," Zeitschrift fur Physik D, vol. 40, no. 1-4, pp. 127-130, 1997.

[18] L. Katsikas, M. Gutiérrez, and A. Henglein, "Bimetallic colloids: silver and mercury," Journal of Physical Chemistry, vol. 100, no. 27, pp. 11203-11206, 1996.

[19] P. Mulvaney and A. Henglein, "Long-lived nonmetallic silver clusters in aqueous solution: a pulse radiolysis study of their formation," Journal of Physical Chemistry, vol. 94, no. 10, pp. 4182-4188, 1990.

[20] A. Henglein, P. Linnert, and P. Mulvaney, Berichte der BunsenGesellschaft für Physikalische Chemie, vol. 94, pp. 1449-1457, 1990.

[21] A. Henglein, P. Mulvaney, and T. Linnert, "Chemistry of silver aggregates in aqueous solution: non-metallic oligomers and metallic particles," Electrochimica Acta, vol. 36, no. 11-12, pp. 1743-1745, 1991.

[22] A. Henglein, P. Mulvaney, and T. Linnert, "Chemistry of $\mathrm{Ag}$ aggregates in aqueous solution: non-metallic oligomeric clusters and metallic particles," Faraday Discussions, vol. 92, pp. 31-44, 1991.

[23] A. Henglein, "Chemical and optical properties of small metal particles in aqueous solution," Israel Journal of Chemistry, vol. 33, pp. 77-88, 1993.

[24] A. Henglein, "Electronics of colloidal nanometer particles," Berichte der Bunsen-Gesellschaft für Physikalische Chemie, vol. 99, pp. 903-913, 1995.

[25] A. Henglein, Berichte der Bunsen-Gesellschaft für Physikalische Chemie, vol. 81, pp. 556-561, 1977.

[26] P. Mulvaney, "Surface plasmon spectroscopy of nanosized metal particles," Langmuir, vol. 12, no. 3, pp. 788-800, 1996.

[27] F. Strelow, A. Fojtik, and A. Henglein, "Chemisorption of phosphine on colloidal silver in aqueous solution," Journal of Physical Chemistry, vol. 98, no. 11, pp. 3032-3035, 1994.

[28] C. G. Blatchford, O. Siiman, and M. Kerker, "Potential dependence of surface-enhanced Raman scattering from citrate on colloidal silver," Journal of Physical Chemistry, vol. 87, no. 14, pp. 2503-2508, 1983. 
[29] M. Treguer, C. De Cointet, H. Remita et al., "Dose rate effects on radiolytic synthesis of gold-silver bimetallic clusters in solution," Journal of Physical Chemistry B, vol. 102, no. 22, pp. 4310-4321, 1998.

[30] N. Toshima, M. Harada, T. Yonezawa, K. Kushihashi, and K. Asakura, "Structural analysis of polymer-protected $\mathrm{Pd} / \mathrm{Pt}$ bimetallic clusters as dispersed catalysts by using extended $\mathrm{X}$ ray absorption fine structure spectroscopy," Journal of Physical Chemistry, vol. 95, no. 19, pp. 7448-7453, 1991.

[31] K. Torigoe, Y. Nakajima, and K. Esumi, "Preparation and characterization of colloidal silver-platinum alloys," Journal of Physical Chemistry, vol. 97, no. 31, pp. 8304-8309, 1993.

[32] A. V. Singh, R. Patil, M. B. Kasture, W. N. Gade, and B. L. V. Prasad, "Synthesis of Ag-Pt alloy nanoparticles in aqueous bovine serum albumin foam and their cytocompatibility against human gingival fibroblasts," Colloids and Surfaces B, vol. 69, no. 2, pp. 239-245, 2009.

[33] C. M. Doudna, M. F. Bertino, F. D. Blum et al., "Radiolytic synthesis of bimetallic Ag-Pt nanoparticles with a high aspect ratio," Journal of Physical Chemistry B, vol. 107, no. 13, pp. 2966-2970, 2003.

[34] C. De Cointet, J. Khatouri, M. Mostafavi, and J. Belloni, "Coalescence and reactivity of gold-silver bimetallic clusters in cyanide solution," Journal of Physical Chemistry B, vol. 101, no. 18, pp. 3517-3522, 1997.

[35] L. M. Liz-marzan and A. P. Philipse, "Stable hydrosols of metallic and bimetallic nanoparticles immobilized on imogolite fibers," Journal of Physical Chemistry, vol. 99, no. 41, pp. 15120-15128, 1995.

[36] N. Toshima, M. Harada, Y. Yamazaki, and K. Asakura, "Catalytic activity and structural analysis of polymer-protected gold-palladium bimetallic clusters prepared by the simultaneous reduction of hydrogen tetrachloroaurate and palladium dichloride," Journal of Physical Chemistry, vol. 96, no. 24, pp. 9927-9933, 1992.

[37] Y. Mizukoshi, K. Okitsu, Y. Maeda, T. A. Yamamoto, R. Oshima, and Y. Nagata, "Sonochemical preparation of bimetallic nanoparticles of gold/palladium in aqueous solution," Journal of Physical Chemistry B, vol. 101, no. 36, pp. 7033-7037, 1997.

[38] H. Remita, A. Etcheberry, and J. Belloni, "Dose rate effect on bimetallic gold-palladium cluster structure," Journal of Physical Chemistry B, vol. 107, no. 1, pp. 31-36, 2003.

[39] C. Damle, A. Kumar, and M. Sastry, "Synthesis of $\mathrm{Ag} / \mathrm{Pd}$ nanoparticles and their low-temperature alloying within thermally evaporated fatty acid films," Journal of Physical Chemistry B, vol. 106, no. 2, pp. 297-302, 2002.

[40] K. Torigoe, H. Remita, P. Beaunier, and J. Belloni, "Radiationinduced reduction of mixed silver and rhodium ionic aqueous solution," Radiation Physics and Chemistry, vol. 64, no. 3, pp. 215-222, 2002.

[41] J. W. T. Spinks and R. J. Woods, An Introduction to Radiation Chemistry, John Wiley \& Sons, New York, NY, USA, 1964.

[42] S. S. Joshi and M. K. Temgire, Research Journal of Chemistry and Environment, vol. 6, pp. 8-11, 2002.

[43] M. K. Temgire and S. S. Joshi, "Optical and structural studies of silver nanoparticles," Radiation Physics and Chemistry, vol. 71, no. 5, pp. 1039-1044, 2004.

[44] G. W. Arnold and J. A. Borders, "Aggregation and migration of ion-implanted silver in lithia-alumina-silica glass," Journal of Applied Physics, vol. 48, no. 4, pp. 1488-1496, 1977.

[45] K. L. Kelly, E. Coronado, L. L. Zhao, and G. C. Schatz, "The optical properties of metal nanoparticles: the influence of size, shape, and dielectric environment," Journal of Physical Chemistry B, vol. 107, no. 3, pp. 668-677, 2003.

[46] G. Mie, "Beiträge zur optik trüber medien, speziell kolloidaler metallösungen," Annalen der Physik, vol. 25, pp. 377-445, 1908.

[47] C. V. Fragstein and H. Römer, "Über die Anomalie der optischen Konstanten," Zeitschrift für Physik, vol. 151, no. 1, pp. 54-71, 1958.

[48] H. Römer and C. V. Fragstein, "Bestimmung des Absorptionskoeffizienten und des Brechungsquotienten von kolloidalem Gold-Ein Beitrag zur "Anomalie der optischen Konstanten"," Zeitschrift für Physik, vol. 163, no. 1, pp. 27-43, 1961.

[49] C. von Fragstein and F. J. Schoenes, "Absorptionskoeffizient und Brechungsindex feinster Goldkugeln im nahen Ultrarot," Zeitschrift für Physik, vol. 198, no. 5, pp. 477-493, 1967.

[50] V. V. Truong and G. D. Scott, "Optical properties of aggregated noble metal films," Journal of the Optical Society of America, vol. 67, pp. 502-510, 1977.

[51] E. Anno, M. Tanimoto, and T. Yamaguchi, "Size-dependent change in the d bands of Cu particles," Physical Review B, vol. 38 , no. 5, pp. 3521-3524, 1988.

[52] J. A. Creighton and D. G. Eadon, "Ultraviolet-visible absorption spectra of the colloidal metallic elements," Journal of the Chemical Society, Faraday Transactions, vol. 87, no. 24, pp. 3881-3891, 1991.

[53] J. F. Rivadulla, M. C. Vergara, M. C. Blanco, M. A. LópezQuintela, and J. Rivas, "Optical properties of platinum particles synthesized in microemulsions," Journal of Physical Chemistry B, vol. 101, no. 44, pp. 8997-9004, 1997.

[54] U. Kreibig and M. Vollmer, Optical Properties of Metal Clusters, vol. 25, Springer, Berlin, Germany, 1995.

[55] E. Rohloff, "Eine optische Untersuchung der plastischen Verformung von Silberchlorid," Zeitschrift für Physik A, vol. 132, pp. 643-654, 1952.

[56] A. Henglein, P. Mulvaney, T. Linnert, and A. Holzwarth, "Surface chemistry of colloidal silver: reduction of adsorbed Cd ions and accompanying optical effects," Journal of Physical Chemistry, vol. 96, no. 6, pp. 2411-2414, 1992.

[57] A. Henglein, A. Holzwarth, and P. Mulvaney, "Fermi level equilibration between colloidal lead and silver particles in aqueous solution," Journal of Physical Chemistry, vol. 96, no. 22, pp. 8700-8702, 1992.

[58] F. L. Williams and D. Nason, "Binary alloy surface compositions from bulk alloy thermodynamic data," Surface Science, vol. 45, no. 2, pp. 377-408, 1974.

[59] P. A. King and J. A. Ward, "Radiation chemistry of aqueous poly(ethylene oxide) solutions. I," Journal of Polymer Science, vol. A1, no. 8, pp. 253-262, 1970. 


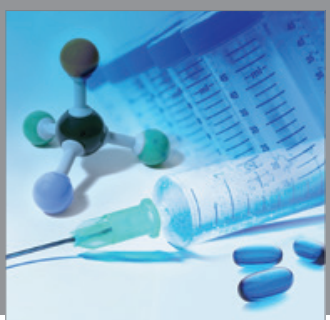

International Journal of

Medicinal Chemistry

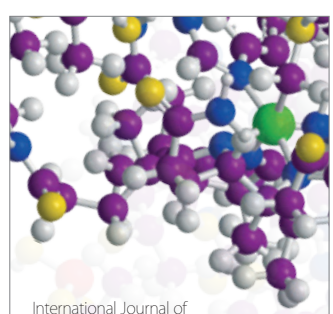

Carbohydrate Chemistry

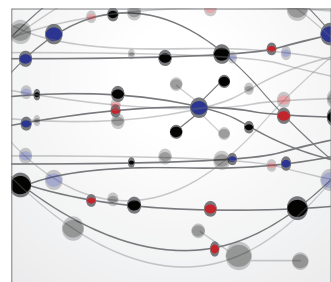

The Scientific World Journal
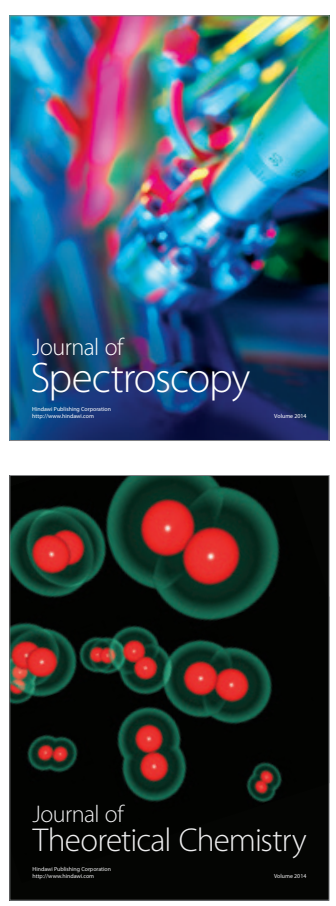
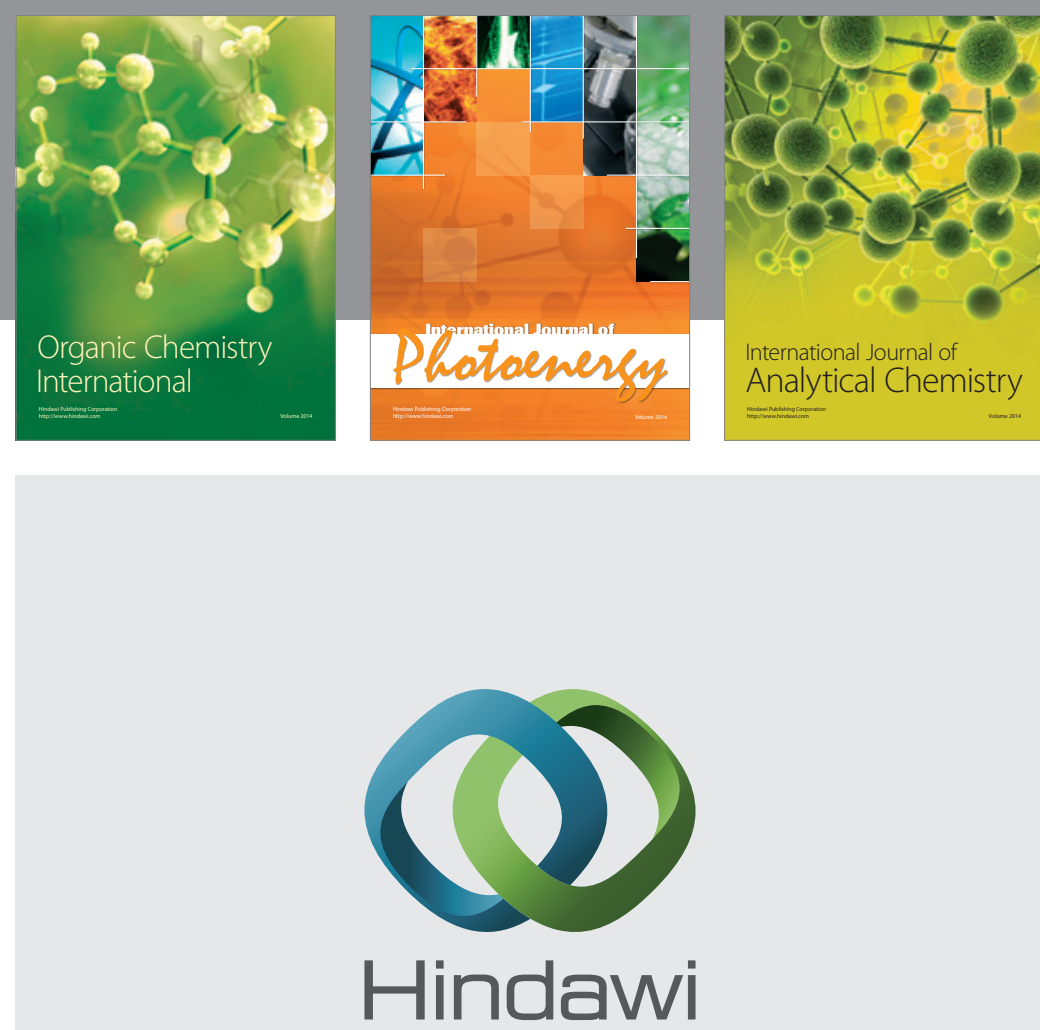

Submit your manuscripts at

http://www.hindawi.com
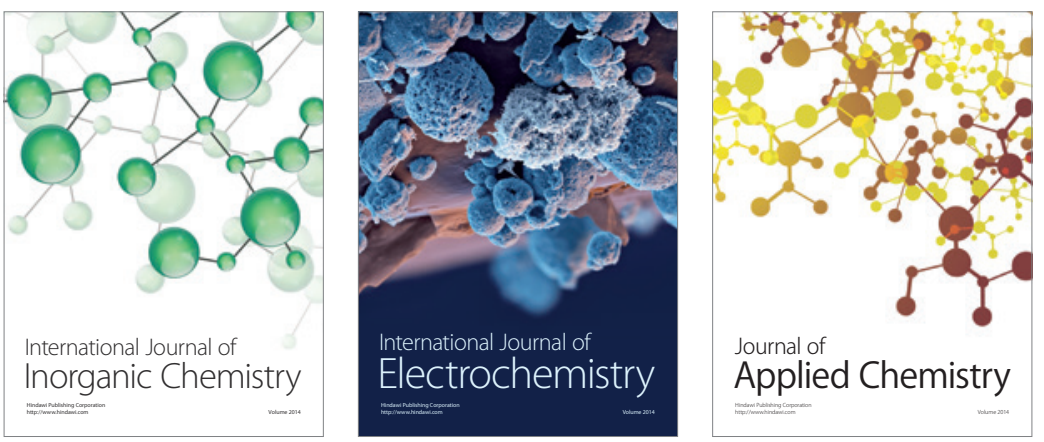

Journal of

Applied Chemistry
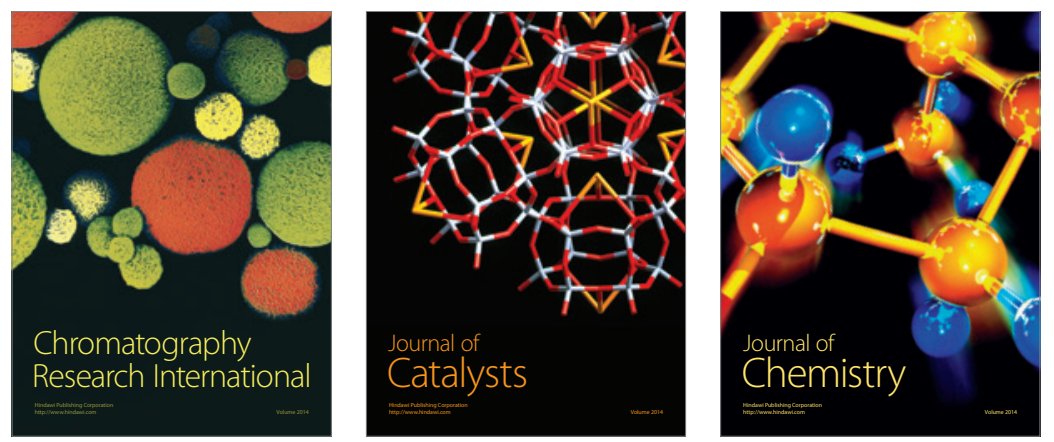
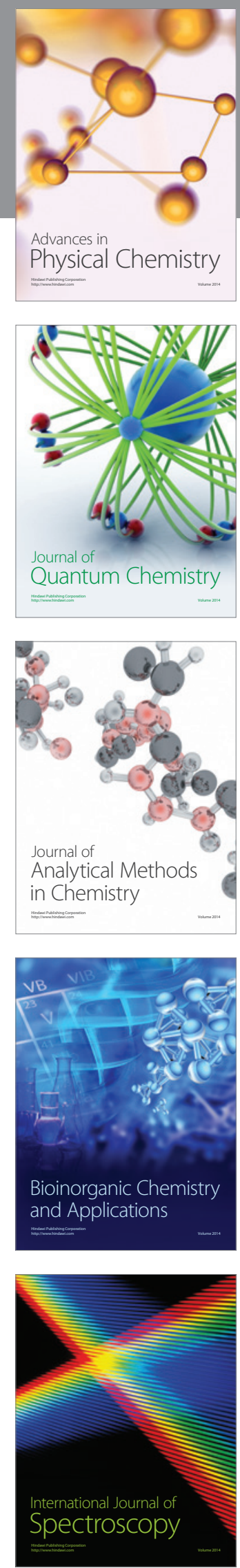